\title{
Pour en lire plus : Habiter la Terre en poète
}

Collectif (2013). Habiter la Terre en poète. Paris : Éditions Les Cabanons, $300 \mathrm{p}$.

\section{Nathalie Calmé}

\section{(2) OpenEdition}

\section{Journals}

Édition électronique

URL : http://journals.openedition.org/ere/580

DOI : $10.4000 /$ ere.580

ISSN : 2561-2271

Éditeur

Centr'ERE

Édition imprimée

Date de publication : 1 septembre 2016

ISSN : 1373-9689

Référence électronique

Nathalie Calmé, «Pour en lire plus : Habiter la Terre en poète », Éducation relative à l'environnement [En ligne], Volume 13 - 1 | 2016, mis en ligne le 15 septembre 2016, consulté le 24 septembre 2020. URL : http://journals.openedition.org/ere/580 ; DOI : https://doi.org/10.4000/ere.580 


\title{
Pour en lire plus : Habiter la Terre en poète
}

\author{
Collectif (2013). Habiter la Terre en poète. Paris : Éditions Les Cabanons,
} $300 \mathrm{p}$.

\section{Nathalie Calmé}

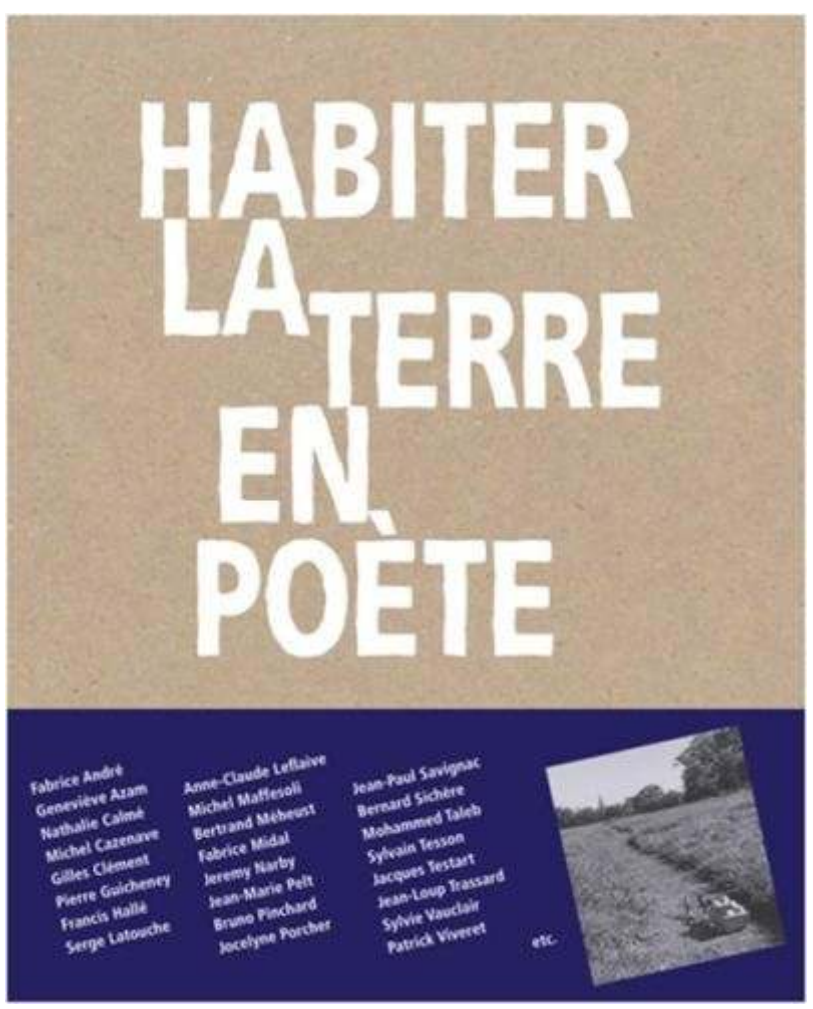

1 D'abord un village, Fontaine-Daniel, en Mayenne, entre Bretagne et Normandie. Ensuite, une fête, la Fête de la Terre. Sa première édition a eu lieu en 2003, autour d'un marché bio et d'un banquet populaire. En fait, cette manifestation, toujours organisée aux alentours du premier week-end de septembre, ne faisait que prolonger, sous d'autres formes, la vieille fête villageoise. Enfin, une association, les Cabanons, qui 
regroupe des habitants autour d'un projet : faire vivre socialement et culturellement le village. Mais si la fête est locale, cela ne signifie nullement qu'elle soit "localiste » ou repliée sur elle-même. Au contraire, un double mouvement s'y exerce : ouverture du village vers le monde, et pénétration, dans le village, des énergies, des nouvelles du monde. Ici, la Terre ne s'entend pas seulement comme le globe terrestre, mais aussi comme la "Terre-patrie», pour prendre une belle expression d'Edgar Morin. Des milliers de personnes rendent visite et participent aux diverses activités de la fête.

2 Pour célébrer son dixième anniversaire, l'association Les Cabanons a voulu marquer le coup en faisant paraitre un livre, un beau livre, un «livre-objet » comme disent les connaisseurs, Habiter la terre en poète. Clin d'œil au romantique allemande Friedrich Hölderlin, le titre pose la possibilité d'un autre mode d'habitation du monde que celui de la prédation, de la domination ou de l'exploitation. Mais ce n'est pas un livre de doux rêveurs. Même si les chapitres sont nombreux, de même que les rédacteurs, le livre est essentiellement structuré selon les Trois écologies du psychanalyste et philosophe Félix Guattari (1930-1992). Celui-ci, dans un essai brillant et méconnu, propose une structuration tripartite de l'écologie. Le premier pôle est l'écologie environnementale, autrement dit le lien à l'environnement naturel (lien qui s'exprime en partie, mais pas uniquement par les " gestes éco-citoyens » individuels); la seconde est l'écologie sociale, avec ses dimensions sociétales, politiques, économiques et juridiques ; et enfin l'écologie mentale, qui est le champ de la subjectivité (individuelle et collective), des valeurs, des représentations culturelles, de la spiritualité aussi. L'association Les Cabanons précise : «Ce livre témoigne du fait que l'écologie ne relève pas seulement du politique ou du médiatique, mais aussi, et même plus sûrement, de la philosophie, de l'art et du sacré. Accompagnés d'une riche iconographie, enserrés dans un graphisme original, les entretiens et les textes proposés nous font entrer dans une intelligence de la Nature faite d'images littéraires, d'expériences professionnelles, de méditations spirituelles. »

3 La première grande partie porte s'intitule : «Une écologie pour prendre soin de la Terre », avec des contributions de Francis Hallé ("Éloge de la forêt»), Anne-Claude Leflaive ("Les forces de vie en viticulture»), Gilles Clément («Toujours la vie invente »), Jocelyne Porcher («Éloge du bien-être de l'animal»), Dominique Florian ( Pour une agriculture paysanne et bioholistique »), Jean-Marie Pelt («Coopération et solidarité dans le vivant»), Claude Henry («Éloge du climat»), Fabrice André ( LL'autonomie énergétique, un chemin vers la liberté »), Sylvie Vauclair (« Habiter la Terre, habiter l'Univers »).

4 La seconde partie, "Une écologie pour changer le monde", comprend des contributions de Geneviève Azam ("Vers un après-capitalisme »), Serge Latouche ("Éloge de la mesure»), Jacques Testart («Pour une science éthique et démocratique »), Patrick Viveret (" Éloge de l'économie solidaire »). Enfin, le troisième pôle de la triade, "Une écologie de la personne humaine", propose des textes de Sylvain Tesson ("L'ermite marcheur»), Michel Maffesoli ("Éloge de l'écosophie»), Mohammed Taleb («Pour un renversement philosophique, éthique, spirituel du capitalisme»), Bruno Pinchard ("Éloge de l'itinérance»), Fabrice Midal («Et si de l'amour on ne savait rien »), Bernard Sichère («À quoi bon des poètes en temps de détresse »), Jeremy Narby («Les plantes, l'intelligence et nous»), Bertrand Méheust ( LL'héritage interdit. Éloge des somnambules »), Pierre Guicheney (« Trésor de Margot, la fée dans la vallée de Saulges »). 
5 Il faut signaler que la formule donnée à ces textes riches et denses est, pour la plupart, celle de l'entretien. Ils ont été réalisés en grande partie par Mohammed Taleb et Nathalie Calmé, qui ont largement contribué à l'émergence du projet et sa réalisation, avec Raphaël Denis, l'animateur de la fête et de l'association Les Cabanons. Par ailleurs, n'oublions pas également une importante section consacrée aux résonances locales de l'ensemble de ces réflexions, à travers des textes de conférence, des entretiens, des témoignages avec les acteurs locaux de la vie sociale, culturelle, et économique (le maire de la commune, des paysans, des enseignants, des artistes, etc.). Le livre est encore riche d'une multitude d'autres aspects (photographies de Bernard Boisson; chroniques cinématographiques; affiches, poèmes ; carnet d'adresses). Habiter la Terre en poète est préfacé par le philosophe jungien Michel Cazenave. Un livre à lire et à offrir.

\section{AUTEUR}

NATHALIE CALMÉ

Écrivaine et journaliste 